Callum Cant | University of West London, UK

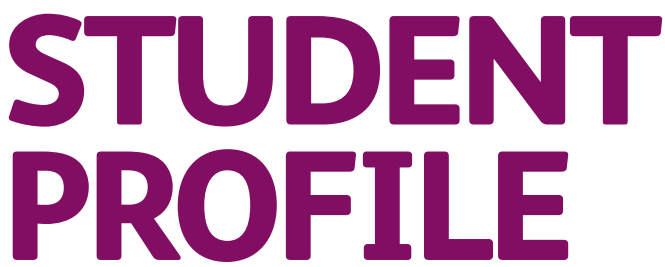

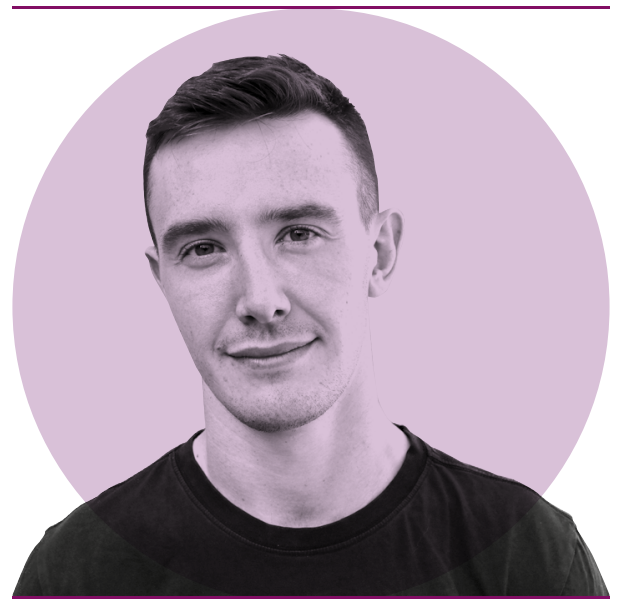

\section{Callum Cant}

Course

PhD in Media

\section{Year completed}

2020

\section{Title of thesis}

"We are a service class": A workers' inquiry into the class composition of service commodity production during the unreal interregnum.
$\mathrm{I}$ $\mathrm{t}$ is half a century since the British workers' movement went into decline. This downwards trajectory was not reversed by the financial crisis of 2008 - in fact, if anything, it was accelerated by it. Levels of working class self-organisation and collective action in the sphere of production remain at historic lows. This lack of activity has left the British working class trapped in a long decade of crisis, subject to a deeply unequal balance of class forces.

Callum's work investigates where this precipitous decline has led us, by using an innovative multi-case-study workers' inquiry methodology to investigate the class composition of one fraction of the contemporary British working class: young, low-paid, service workers who are disconnected from the institutions of the workers' movement. His thesis makes two original contributions.

First, it develops an original theoretical framework for the analysis of class composition on the basis of a 3-part model (technical, social, and political). This framework uses readings from Marx, the socialist feminist tradition, and Lenin in order to analyse working class organisation in the sphere of production through a consistent system of categories based on the materialist analysis of social relations.

Second, it presents the results of a workers' inquiry comprising three case studies on three separate workplaces in Brighton. This study found a class fraction which is subject to intense systems of managerial control-but which also has the capacity to throw those systems into disarray. Below the surface of the service sector, many of the conditions necessary for a rapid shift in the balance of class forces are present. What is missing is a subjective sparkone which could be provided by the significant minority of workers who are sympathetic to political militancy, and whose agitation might prove capable of starting a process of 'associational amplification' through which the fraction first struggles to promote its immediate economic interests, and then leaps into the fight for more fundamental political ones.

He concludes that such a leap, if merged with the concerted efforts of socialists to create mechanisms for the expression of this antagonism at the political level, might offer some way forwards for working class politics.

Completed just as the first Coronavirus lockdown was coming into effect, this thesis offers an empirical snapshot of a class fraction in the moments before the pandemic hit, and a theoretical model through which to understand how processes of development reorganise capitalist social relations.

During the research process, Cant also wrote and published his first book, Riding for Deliveroo. This popular workers' inquiry into the state of class conflict in 'platform capitalism' communicates much of the framework of the thesis in more approachable terms. His scholarly work has been published in journals such as The South Atlantic Quarterly, Capital and Class, ephemera, and Triple $C$, and in popular media outlets such as The Guardian, The Independent, and Vice. He took a break from his PhD research to work on the 2019 General Election campaign with Momentum as the Digital Communications Team Lead, and on completing his thesis, he returned to work as Momentum's Head of Communications. He has now returned to academia, taking up a position as a Postdoctoral Researcher at the Oxford Internet Institute on the Global Partnership for the 'Fair Work for AI' project focusing on regulatory frameworks for artificial intelligence in the workplace.

\author{
Supervisors: \\ Professor Helen Hester \\ Jamie Woodcock and \\ Professor Jeremy Strong \\ Professor Helen Hester \\ is Professor of Gender, Technology, \\ and Cultural Politics, University \\ of West London \\ Dr Jamie Woodcock \\ is Senior Lecturer in Management, \\ Open University \\ Professor Jeremy Strong \\ is Professor of Literature and \\ Film, University of West London
}

